\title{
Pengaruh pendampingan dan penyuluhan oleh mahasiswa kkn terhadap perubahan perilaku pus ber-kb di alu polewali mandar
}

\author{
Andan Firmansyah ${ }^{1}$, M.Syikir ${ }^{2}$, Rusman $^{3}$, Fransiska Firna $^{4}$ \\ ${ }^{1,2,3}$ Prodi Keperawatan STIkes Bina Generasi Polewali Mandar \\ ${ }^{4}$ Prodi Kebidanan STIKes Bina Generasi Polewali Mandar
}

\section{Keywords :}

Assistance, Counseling, Behavior, PUS,

Student KKN

\section{Kontak :}

Andan Firmansyah

Email : andan@biges.ac.id

Prodi Keperawatan STIkes Bina

Generasi Polewali Mandar

Vol 2 No 1 September 2019

DOI: https://doi.org/10.31605/jhealt.v2i1 (C)2018J-Healt

ini adalah artikel dengan akses terbuka dibawah licenci CC BY-NC-4.0

https://creativecommons.org/licenses/by-nc/4.0/

\begin{abstract}
Polewali Mandar Regency is a Disadvantaged Area by 2015-2019 based on Government Regulation no.131 2015 and based on 2015 susenas data, West Sulawesi is in quadrant 2, where the CPR level (contraceptive prevalence rate) is low and TFR (total fertility rate) is high. the purpose of this study was to determine the influence of PENYU of KKN students on the Changes of Behavior of Family Planning Center in the District of Alu Polewali Mandar Regency. This study included Quasi Experimental research. This research will be conducted in Allu Sub-district Polewali Mandar District in two villages of Mombi village as treatment place, and Pao-Pao village as a place of Research Control Assessing the difference between treatment and control with unpaired t-test by scoring all the results of the calculation of knowledge variables, attitudes and behaviors with results there are significant differences in knowledge change between cases and control groups through the involvement of KKN students through the approach of assistance and counseling on PUS. With $p$ value $=0.005$. There is difference of attitude change with value $p$ value $=0,001$. There is $a$ difference of behavior change with $p$ value $=0,013$. Assessing the influence of vaiabel research with Chi-Square test obtained The existence of influence between PENYU KKN students changes in knowledge, attitudes and behavior of PUS in the district alu that is knowledge with $p$ value 0.005 , attitude with $p$ value 0,000 and behavior with value $p$ value 0,000 .
\end{abstract}




\section{PENDAHULUAN}

Kabupaten Polewali Mandar masuk dalam kategori daerah tertinggal yang menempati posisi 74 dari 122 Kabupaten tertinggal yang ada di Indonesia yang ditegaskan oleh Perpres Nomor 131/2015 tentang penetapan daerah tertinggal tahun 2015-2019.

Angka kematian Ibu di Kabupaten Polewali Mandar tahun 2013 adalah 11/1.000 kelahiran hidup, sedangkan AKI tahun 2014 adalah 5/1.000 kelahiran hidup, pada tahun 2015 mengalami peningkatan dengan angka kejadian 15/1.000 kelahiran hidup, sedangkan pada awal tahun 2016 sudah ada 1 kasus kematian ibu. Artinya pada tahun 2015 angka kematian ibu mengalami peningkatan Penyebab kematian yaitu salah satunya infeksi 5,56\% (Dinas Kesehatan Kabupaten Polewali Mandar, 2015).

Data dari Dinas Kesehatan Polewali Mandar jumlah PUS 65.063 Pasangan dan pengguna kontrasepsi sebanyak 32.008 (49\%) pasangan. Data yang diperoleh dari Kec. Alu terdapat 8 desa yaitu desa Mombi 402 PUS, Sayoang 103 PUS, alu 296 PUS, Petoosang 295 PUS, Puppuring 235 PUS, Pao-pao 317 PUS, Saragian 286 PUS, Kalumammang 220 PUS dari 8 desa tersebut desa mombi merupakan desa yang memiliki PUS Terbanyak pada bulan Mei jumlah sasaran PUS terdapat 2154 pasangan, dari keseluruhan data tersebut terdapat $1309(60,77 \%)$ PUS yang menjadi sasaran KB. dari data puskesmas Tutallu jumlah PUS Terbanyak di daerah Mombi Kec. Alu jumlah PUS pada bulan Mei terdapat 402 Pasangan dan yang aktif menggunakan KB ada 240 pasangan atau sekitar $61.96 \%$ artinya jumlah pasangan yang tidak menggunakan KB di wilayah tersebut masih tinggi (Data puskesmas Alu, 2017).

Metode Penyu merupakan proses Pendampingan dan penyuluhan dengan berbagai model dan metode yang berlangsung terus menerus (Continues) dalam waktu tertentu dilakukan oleh semua pihak yang kompeten.Pada penelitian ini metode penyu melibatkan mahasiswa KKN, dimana mahasiswa akan intens menemani keluarga sebagai binaannya selama 2 bulan lamanya. Oleh sebab itu dalam proses Penyuluhan KB tidak hanya menggunakan satu atau dua metoda saja yang dilakukan secara Komprehensif dan terus menerus. Karena untuk meyakinkan keluarga ber $\mathrm{KB}$ adalah merupakan proses belajar terus menerus dan sebelum mengambil keputusan akan selalu diliputi keraguan, ketakutan, kekhawatiran, was-was baik dari sisi harapan sosial, masa depan keluarga maupun dari sisi medis. Dimana Mahasiswa KKN memiliki kesempatan yang baik untuk berinteraksi dan bersentuhan dengan frekuensi yang cukup sering dengan masyarakat sehingga kondisi ini memungkinkan dilaksanakannya penyuluhan dengan metode pendampingan yang lebih intens dan terukur, sehingga harapannya masyarakat dapat memahami lebih mendalam manfaat dari menjadi akseptor KB daripada hanya penyuluhan yang bersifat seremonial. Tapi mahasiswa akan digiring untuk lebih intensif mendekati masyarakat mengkaji dan menemukan solusi yang paling baik dalam memilih kontrasepsi yang terbaik yang dibutuhkan keluarga binaannya..

\section{METODE PENELITIAN}

Penelitian ini termasuk penelitian esperimen semu (Quasi Eksperimental research). penelitian ini menggunakan test awal dan test akhir dengan dua kelompok (pretest-posttest with control group design). (Saryono, 2013). Penelitian ini dilaksanakan di Kecamatan Allu Kabupaten Polewali Mandar di dua desa yaitu desa Mombi sebagai tempat perlakuan, dan desa Pao-Pao sebagai tempat Kontrol. Penelitian ini dilaksanakan pada bulan juniagustus tahun 2017. Adapun sampel dalam penelitian ini sebanyak 200 pasangan usia subur yang belum ber-KB yang terdiri dari 100 perlakuan dan 100 kontrol. Pengumpulan data dilakukan dengan menggunakan kuesioner untuk mengkaji pengetahuan dan sikap PUS dan observasi untuk mengetahui perilaku dan kegiatan Penyu oleh mahasiswa KKN. Pengolahan dilakukan dengan membuat total skor masing-masing komponen penilaian 
untuk masing-masing variabel pengetahuan sikap dan perilaku pada kelompok perlakuan dan kontrol. Kemudian dilakukan uji normalitas data apabila berdistribusi normal maka dilakukan uji t. Data selanjutnya dianalisis distribusi frekuensi univariat dan dilakukan uji bivariate antar variable perlakuakn dan control dengan uji t dengan alternative man withney dan uji chi-square dengan alternative fisher untuk melihat seberapa besar pengaruh penyu terhadap perubahan perilaku PUS.

\section{HASIL DAN PEMBAHASAN}

Perbedaan antara pengetahuan, sikap dan perilaku Desa Pao-Pao (Tidak diberikan PENYU) dan Desa Mombi (diberikan PENYU) dapat dilihat pada tabel dibawah ini :

Tabel 1. Perbedaan antara pengetahuan, sikap dan perilaku Desa Pao-Pao dan Desa Mombi

\begin{tabular}{|c|c|c|c|c|c|}
\hline Varia & & $\begin{array}{l}\text { Pre } \\
\text { Momb } \\
\text { i }\end{array}$ & $\begin{array}{l}\text { Post } \\
\text { Momb } \\
\text { i }\end{array}$ & $\begin{array}{l}\text { Pre } \\
\text { Pao } \\
-\end{array}$ & $\begin{array}{l}\text { Pos } \\
\text { t } \\
\text { Pao }\end{array}$ \\
\hline Item & $\begin{array}{l}\text { Kriteri } \\
\text { a }\end{array}$ & $\sum(\%)$ & $\sum(\%)$ & $\sum_{(\%)}$ & $\sum_{(\%)}$ \\
\hline Peng & Baik & 27 & 35 & 23 & 23 \\
\hline & Cukup & 31 & 39 & 34 & 36 \\
\hline $\begin{array}{l}\text { ta } \\
\text { huan }\end{array}$ & Kurang & 42 & 26 & 43 & 41 \\
\hline Sika & Positif & 37 & 59 & 20 & 29 \\
\hline p & Negatif & 63 & 41 & 80 & 71 \\
\hline Prila & Positif & 0 & 21 & 0 & 3 \\
\hline $\mathbf{K u}$ & Negatif & 100 & 79 & 100 & 97 \\
\hline
\end{tabular}

Tabel 2. hasil analisis uji normalitas setiap Desa dan uji Wilcoxon Test

\begin{tabular}{|c|c|c|c|c|c|c|}
\hline \multicolumn{2}{|c|}{ Variabel } & \multicolumn{2}{|c|}{$\begin{array}{l}\text { Mombi } \\
(n=100)\end{array}$} & \multicolumn{2}{|c|}{$\begin{array}{l}\text { Pao- } \\
\text { Pao(n=10 } \\
\text { 0) }\end{array}$} & \multirow{2}{*}{$\begin{array}{l}\text { Wilc } \\
\text { o- } \\
\text { xon } \\
\text { (P) }\end{array}$} \\
\hline Item & $\begin{array}{l}\text { Krit } \\
\text { eria }\end{array}$ & $\begin{array}{l}\text { M+ } \\
\text { SD }\end{array}$ & $\mathrm{P}$ & $\begin{array}{l}\text { M+ } \\
\text { SD }\end{array}$ & $\mathbf{P}$ & \\
\hline \multirow[t]{2}{*}{$\begin{array}{l}\text { Peng } \\
\text { etah } \\
\text { uan }\end{array}$} & Pre & $\begin{array}{l}17 \\
77+ \\
3,5 \\
50\end{array}$ & $\begin{array}{l}, 00 \\
0\end{array}$ & $\begin{array}{c}17,5 \\
5+3 \\
, 341\end{array}$ & $\begin{array}{l}, 00 \\
0\end{array}$ & \multirow[t]{2}{*}{,005 } \\
\hline & Post & $\begin{array}{l}19, \\
04+ \\
3,3 \\
57\end{array}$ & $\begin{array}{l}, 00 \\
0\end{array}$ & $\begin{array}{c}17,7 \\
3+3 \\
, 372\end{array}$ & $\begin{array}{l}, 00 \\
0\end{array}$ & \\
\hline \multirow[t]{2}{*}{$\begin{array}{l}\text { Sika } \\
\text { p }\end{array}$} & Pre & $\begin{array}{l}33 \\
72+ \\
6,5 \\
01\end{array}$ & $\begin{array}{l}, 00 \\
0\end{array}$ & $\begin{array}{l}35,9 \\
2+ \\
6,05\end{array}$ & $\begin{array}{l}, 00 \\
0\end{array}$ & \multirow[t]{2}{*}{,001 } \\
\hline & Post & $\begin{array}{l}39, \\
14+ \\
5,9 \\
98\end{array}$ & $\begin{array}{l}, 00 \\
0\end{array}$ & $\begin{array}{l}37 \\
+6, \\
558\end{array}$ & $\begin{array}{l}, 00 \\
0\end{array}$ & \\
\hline \multirow[t]{2}{*}{$\begin{array}{l}\text { Prila } \\
\text { ku }\end{array}$} & Pre & $\begin{array}{l}3,8 \\
1+0 \\
, 39 \\
4\end{array}$ & $\begin{array}{l}, 00 \\
0\end{array}$ & $\begin{array}{l}3,51 \\
+0 \\
823\end{array}$ & $\begin{array}{l}, 00 \\
0\end{array}$ & \multirow[t]{2}{*}{013} \\
\hline & Post & $\begin{array}{l}4,2 \\
5+1 \\
, 47 \\
3\end{array}$ & $\begin{array}{l}, 00 \\
0\end{array}$ & $\begin{array}{l}3,55 \\
+0 \\
880\end{array}$ & $\begin{array}{l}, 00 \\
0\end{array}$ & \\
\hline
\end{tabular}

Berdasarkan data pada tabel diatas didapatkan nilai signifikansi untuk pengetahuan sebesar 0.005. untuk nilai sifnifikansi sikap sebesar 0,001 dan nilai signifikansi untuk perilaku sebesar 0,013. Dari ketiga nilai signifikansi tersebut semuanya lebih kecil dari nilai $\alpha=$ 0.05 artinya ada perbedaan yang signifikan antara pre dan post pada kelompok perlakuan dengan pre dan post pada kelompok control. 
Masuk ke analisi pengaruh Penyu terhadap perubahan perilaku dapat dilihat pada table 3 .

Tabel 3. Tabulasi Silang Antara pendampingan dan penyuluhan (PENYU) dengan Perilaku PUS

\begin{tabular}{|c|c|c|c|c|c|c|c|}
\hline \multirow{3}{*}{$\begin{array}{l}\text { PENY } \\
\text { U }\end{array}$} & \multicolumn{4}{|c|}{ Perilaku } & \multicolumn{2}{|c|}{ Jumlah } & \multirow{3}{*}{$\begin{array}{l}p- \\
\text { value }\end{array}$} \\
\hline & \multicolumn{2}{|c|}{ Positif } & \multicolumn{2}{|c|}{ Negatif } & & & \\
\hline & f & $\%$ & $\mathbf{f}$ & $\%$ & $\mathbf{f}$ & $\%$ & \\
\hline $\begin{array}{l}\text { Diberik } \\
\text { an }\end{array}$ & 21 & 10,5 & 79 & $\begin{array}{l}39, \\
5\end{array}$ & $\begin{array}{l}10 \\
0\end{array}$ & 50 & \\
\hline $\begin{array}{l}\text { Tdk } \\
\text { diberik } \\
\text { an }\end{array}$ & 3 & 1,5 & 97 & $\begin{array}{l}48, \\
5\end{array}$ & $\begin{array}{l}10 \\
0\end{array}$ & 50 & 0.000 \\
\hline $\begin{array}{l}\text { Jumla } \\
\text { h }\end{array}$ & 24 & 12 & $\begin{array}{l}17 \\
6\end{array}$ & 88 & $\begin{array}{l}20 \\
0\end{array}$ & 100 & \\
\hline
\end{tabular}

Hasil analisis data dengan menggunakan statistik uji chi-square diperoleh nilai p-value sebesar 0.000 yang artinya ada pengaruh antara penyu oleh mahasiswa KKN terhadap perubahan perilaku PUS.

\section{KESIMPULAN}

1. Karakteristik pasangan usia subur di kecamatan alu terlihat dari segi umur ibu masih lebih banyak pada usia 20-35 tahun sekitar 81-83\%, umur menikah pus lebih banyak pada rentang usia 20-35 tahun sebanyak $58-63 \%$, lama menikah paling tinggi 0-5 tahun yaitu 41-53\%, paritas pus paling tinggi grandmultipara sekitar 24-33 $\%$, pendidikan rersponden pada rentang pendidikan rendah sekitar 48-58 \%, dan pekerjaan lebih banyak Ibu rumah tangga sekitar 70-81\%.

2. Tingkat pengetahuan Pus di awal penyu rendah sekitar $42-43 \%$ dan sikap negatif sekitar $63-80 \%$ sedangkan prilaku negatif $100 \%$ di duas desa, namun setelah intervensi penyu di desa mombi mengalami perubahan di pengetahuan menjadi baik sekitar $35 \%$ m, sikap positif $59 \%$ dan prilaku masih dalam rentang negatif $79 \%$, namun di desa pao-pao pengetahuan rendah sekitar $41 \%$, Sikap negatif $71 \%$, dan prilaku negatif $97 \%$.

3. Dalam proses pendampingan dan penuluhan (penyu) Mahasiswa KKN kepada pasangan usia subur, mulai pembekalan, pengkajian dan implementasi pendampingan dan penyuluhan $95 \%$ terlibat dan aktif dari 50 mahasiswa.

4. Ada perbedaan yang signifikan perubahan pengetahuan antara kelompok kasus dan kontrol melalui keterlibatan mahasiswa KKN melalui pendekatan pendampingan dan penyuluhan (penyu) pada PUS. Dengan nilai $p$ value $=0,005$. Ada perbedaan perubahan sikap antara kelompok kasus dan kontrol melalui keterlibatan mahasiswa KKN melalui pendekatan pendampingan dan penyuluhan (penyu) pada PUS. Dengan nilai $\mathrm{p}$ value $=$ 0,001 . Ada perbedaan perubahan perilaku antara kelompok kasus dan kontrol melalui keterlibatan mahasiswa KKN melalui pendekatan pendampingan dan penyuluhan (penyu) pada PUS. Dengan nilai $\mathrm{p}$ value $=$ 0,013

5. Adanya pengaruh antara pendampingan dan penyuyluhan (Penyu) mahasiswa KKN terhadapa perubahan pengetahuan, sikap dan prilaku PUS di kecamatan alu yaitu pengetahuan dengan $\mathrm{p}$ value 0,005 , sikap dengan $p$ value 0,000 dan prilaku dengan nilai $p$ value 0,000 


\section{DAFTAR PUSTAKA}

Arikunto, Suharsimi. 2002. Prosedur Penelitian Pendekatan Praktek, Edisi Revisi V. Jakarta: Rineka Cipta.

Barbara R 2005.Panduan Belajar Keperwatan Ibu-Bayi Baru Lahir. Jakarta:

\section{kedokteran ECG}

BKKBN,2009 Tunda Kehamilan Dengan Alat Kontrasepsi Yang Tepat .Diakses 2

Mei 2010.

Bobak, Lowdermilk, Jansen. 2005. Buku Ajar Keperawatan Maternitas. Edisi 4. Jakarta : EGC.

Burhan,Zulfiah. 2014. Hubungan Antara Pengetahuan dan Sikap Pus dengan Ketidak Ikutsertaan ber-KB di Dusun Garassi Desa Napo Kecamatan Wonomulyo Kabupaten Polewali Mandar.Skripsi.STIKES Bina Generasi Polewali mandar

Data Puskesmas Alu, 2017

Depkes RI. 2007. Standar Pelayanan Kebidanan. Jakarta : Depkes RI

Depkes RI. 2007. Profil Kesehatan Indonesia. Jakarta

Depkes 2012.Gizi Kita.http://www.gizi kita.,go.id.3. Januari 2014

Gunawan. 2007. Hipertensi Tekanan Darah Tinggi. Yogyakarta: Kanisius.

Ary H. Gunawan, 2000 Sosiologi Pendidikan: Suatu Analisis Sosiologi Tentang Pelbagai Problem Pendidikan. Rineka Cipta

Hidayat, Aziz Alimul. 2008. Pengantar Ilmu Kesehatan Anak Untuk Pendidikan Bidan. Jakarta: EGC

Maryam,S. Analisis persepsi ibu tentang program Keluarga Berencana ( $\mathrm{KB}$ ) dengan penggunaan kontrasepsi. Jurnal Universitas Tulungagung BONOROWO Vol.1.NO.2 tahun 2014
Machfoedz Ircham. 2016. Metodologi Penelitian Kuantitatif \& Kualitatif Bidang Kesehatan, Keperawatan, Kebidanan, Kedokteran. Fitramaya. Yogyakarta

Notoatmodjo S.2010. Metodologi Penelitian Kesehatan Jakarta : PT.Rineka Cipta.

Notoatmodjo, Soekidjo, 2010. Metodologi Penelitian Kesehatan. Jakarta., Edisi Revisi, Penerbit Rineka Cipta.

Notoatmodjo, S, 2007. Promosi kesehatan dan ilmu perilaku. PT Rineka Cipta. Jakarta.

Notoatmodjo, S, 2003. Ilmu kesehatan masyarakat; prinsip-prinsip dasar. Cetakan kedua. PT Rineka Cipta. Jakarta.

Novita paradina,Nimas.2014. Strategi Komunikasi Penyuluh Lapangan Keluarga Berencana Dalam Partisipasi Pasangan Usia Subur Pada Progrman Keluarga Berencana Di Kota Samarinda. Skripsi. Universitas Mulawarman

Nurmahdalena, Annisa, 2016. Peran Penyuluh Keluarga Berencana (PKB) Dalam Pengendalian Pertumbuhan Penduduk Di Kelurahan Sungai Dama Ecamatan Samarinda Ilir. Skripsi. Universitas Mulawarman

Nursalam. 2016. Metodologi Penelitian Ilmu Keperawatan : Pendekatan Praktis. Salemba Medika. Jakarta

Pahlupi,Riza.2012. Hubungan Antara Kegiatan Penyuluhan Program KB dengan Perubahan Sikap Penduduk Di Kecamatan Bayombong Kabupaten Garut.

Prawirohardjo Sarwono, 2012. Ilmu Kebidanan, Jakarta :Penerbit PT Bina Pustaka Sarwono Prawirohardjo.

Profil Dinas Kesehatan kabupaten polewali mandar, 2016 
Profil dinas kesehatan provinsi Sulawesi barat, 2016

Manuaba, IGD. 1998. Ilmu Kebidanan Penyakit Kandungan dan Keluarga Berencana untuk Pendidikan Bidan.Jakarta: EGC.

Nursalam. 2003. Konsep dan Penerapan Metodologi Penelitian Ilmu Keperawatan. Jakarta: Salemba Medika.

Prawirohardjo, S. 2005. Ilmu Kebidanan. Jakarta : PT. Bina Pustaka Sarwono Prawirohardjo.

Saifudin, AB. 2006. Pelayanan Kesehatan Maternal dan Neonatal. Jakarta: Yayasan Bina Pustaka Sarwono Prawirohardjo.

Saifuddin BA 2008 Buku Panduan Praktis Pelayanan Kontrasepsi. Jakarta Yayasan Bina Pustaka

Sry handayani 2010. Buku Ajar pelayanan Keluarga Berencana Yokyakarta : Rihama

Sri handayani 2009 Kerja Sama Pusat Penelitian Kependudukan, Universitas Gadjah Mada

Sulistyowaty 2011 Buku Panduan Tentang Gender Di Parlemen. Sekretariat Jenderal DPR RI, 2009

Suratun,dkk. Pelayanan Keluarga Berencana Dan Pelayanan Kontrasepsi. Ed.1. Trans Info Media. Jakarta.2008

Saryono, Mekar dwi anggraeni. 2013. Metodologi Penelitian Kualitatif dan Kuantitatif dalam Bidang Kesehatan. Nuha Medika. Yogyakarta.

Semmaila Baharuddin; Reza Aril Ahri. 2017. Metodologi Penelitian Kuantitatif. Arus Timur. Makassar.

KBBI. 2008, Ed.4.Depdiknas.PT Gramedia Pustaka Utama.Jakarta.

Wawan, A., \& dewi, M, 2010.Teori Dan Pengukuran Pengetahuan, Sikap,Dan
Perilaku Manusia. Yokyakarta: penerbit Nuha medika 